\title{
Cost-Resource Replacement Trade-off Algorithm for Multi-Skilled Resource Scheduling
}

\author{
Narongrit Wongwai ${ }^{\mathrm{a} *}$ and Suphawut Malaikrisanachalee ${ }^{\mathrm{b}}$ \\ a Department of Civil Engineering, Kasetsart University Sriracha Campus, Chonburi, Thailand. \\ ${ }^{b}$ Department of Civil Engineering, Kasetsart University, Bangkok, Thailand. \\ *Corresponding author: Narongrit Wongwai \\ ORCIDs: 0000-0002-8056-6260 (Narongrit), 0000-0001-9031-457X (Suphawut)
}

\begin{abstract}
Conventional single-skilled resource scheduling uses heuristic rules to decide which activities have higher priority and hence they have the privilege to claim resources first while other activities with lower priority will receive remaining resources. Some activities have to be delayed unless their required resources can be completely fulfilled. This, in effect, seems to be unreasonable while construction project will be delayed just the only one insufficient resource, especially in large-scale project. Existing multi-skilled resource scheduling is greedy where it relies on replacing the insufficient resources immediately whereas the financial worthiness is not take into consideration. This research presents cost-resource replacement trade-off algorithm where the resource replacement cost and the one-day delaying activity cost are compared before to decide whether to replace the insufficient resources or to delay the activity. Project float is used to indicate penalty cost occurred when the project goes beyond the contract time. Total float is considered to avoid unnecessary cost from the resource replacement for non-critical activity and increased project completion from delaying the critical activity. Several project case studies illustrate that it guarantees significant minimum project cost due to better decision-making process for resource scheduling.
\end{abstract}

Keywords: Resource scheduling, resource replacement, multiskilled resource scheduling, minimum project cost.

\section{INTRODUCTION}

Construction project includes activities which require the use of resources in order to achieve its goals. The basic resources necessary for the project are man, money, method, material and machine. However, since the mentioned resources are limited as some days there were more than an activity demanding on the same resources, the shortage of resources becomes unavoidable. This results in the delay of project finish time and the increase of project cost. Researches related to resourcesconstrained project scheduling conducted by those interested scholars during the long decades have provided numerous methods of study. One among them is exact solution method such as dynamic programming [10], implicit enumeration with branch and bound [20] and zero-one programming [30,31,3334]. Another one is metaheuristic method like ant colony [29], genetic algorithm [13-14,15,18,27-28,38], simulated annealing $[3,5,8,35]$ and tabu search $[32,36]$ It is observed that despite being optimal and nearly optimal solution, both the methods lead to time consuming due to the complicated aspect of the problem in resources constrained project scheduling known as NP hard problem. In the worst case, sometimes they may lead to combinatorial explosion. It is therefore not suitable in practice.

Heuristic method is an alternative way of study to find out the solution with simple rules. The method contributes to nearly optimal solution and sometimes gives optimal solution. Because of the ability of finding out the solution fast, it is suitable for the complicated problems. Heuristic method is generally used for resources-constrained project scheduling. It involves in heuristic rules focusing on priority order of the activities that demand the same resources on the same day. According to the method, the resources are first given to the higher priority activities, then the resources will be given to the lower priority activities accordingly. Although, there are some differences in various methods of heuristic rules $[1-2,4,6,7$, $9,11-12,17,19,21-26,37,39]$, they share the same assumption that each resource has only single skill. However, this assumption is not in conformity with the reality of construction projects containing of some workers who are capable of multiskills. It is also found that in some occasions when the number of workers is not enough, the workers may be assigned to cope with the unfamiliar activities. Besides, a number of researches in the past demonstrates that the project scheduling assuming that a resource has only single skill causes the inefficient resource utilization. As a result, the project finish time is delayed and the project cost increase unnecessarily.

Heuristic method developed by Hegazy et. al. [16] aimed to improve traditional single-skilled resource allocation procedure by allowing insufficient resources to be replaced with other multi- skill resources. For example, two steel workers who have half productivity of formwork can be replaced a carpenter when there is a shortage of carpenters in the construction sites. This method helps in the starting time of a critical activity instead of being delayed which could reduce the project finish time.

AHAMRS proposed by Wongwai et. al. [40] has improved the 
process of multi-skilled resource scheduling by rearrange the sequence of resource assign and resource replacement so that the two processes would run more efficiently. It starts with resource assignment in vertical direction where available resources are assigned matching with exact resource requirement to all current eligible activities following with priority order regardless of insufficient resources. This method also presents the concept of resource-driven task duration where an activity that is not under the team constrained condition can start with partial resource fulfilment in order to increase starting opportunity of activities at earlier time. The results on various case studies demonstrate that AHAMRS can significantly reduce the project duration compared to resourceconstrained scheduling approaches.

\section{LIMITATION OF EXISTING RESOURCE SCHEDULING APPROACH}

\section{Critical activity consideration}

Existing single-skilled resource-constrained project scheduling relies on the principal of delaying an activity with insufficient resources. If the respective activity is considered to be critical, the one-day delay of the critical activity results in one-day delay of the project finish time. Consequently, the indirect and opportunity cost increase. Moreover, the delay of project finish time that goes beyond the contract time would automatically cause penalty cost. To say in short, the approach of existing single skilled resource constrained project scheduling seems to be unreasonable in solving the problem of resource shortage especially in the large-scale construction project which is subjected to high amount of daily indirect cost, daily opportunity cost and daily penalty cost when compared with the resource cost per unit. This is a reason why the expenditure derived from all increased cost in the large-scale project due to one-day delay of project is unworthy when considering the fact that the project lacks just the only one resource. Drawing from the mentioned reasons, it is therefore unavoidable to state that the substitution of the insufficient resources with multi-skilled resources and/or external resources provides better solution to the concerned problem as shown in a simple example of Fig. 1.

According to bar chart in Fig. 1, since activity B and C proceed parallelly, the demand on resource $\mathrm{R} 1$ exceed the available resources on the third and fourth day of work. The first solution for the problem by delaying critical activity c, having lower priority when compared with activity $\mathrm{B}$, in spite of being able to solve the problem of insufficient resource $\mathrm{R} 1$, it creates the delay of project finish time for two-days, from the sixth day to the eighth day. Besides, it results in the increased project cost from 9,000 Baht to 11,400 Baht. The change on project finish time (from sixth day to eight days) and project cost (from 9,000 Baht to 11,400 Baht) is in fact based its calculation on the idea that the resources are limited. The study also focuses on the other alternative solution. The second solution replaces a unit of resource R1 with two units of resource R2 on the third and the fourth day of work. This solution emphasizes on the difference of capability between $\mathrm{R} 1$ and $\mathrm{R} 2$ as it is evident that $\mathrm{R} 2$ acquires about half of productivity of $\mathrm{R} 1$. As a result, the project finish time is not delay. In addition, the project cost is cheaper than the first solution. In conclusion before deciding to delay an activity due to insufficient resources, it is necessary to consider whether that particular activity is a critical activity or not because the delay of critical activity may cause the delay of project finish time and the increase of project cost.

\section{Non - critical activity consideration}

The existing multi-skilled resource-constrained project scheduling decides to choose the rest of multi-skilled resources to substitute the insufficient resources immediately. If the activity having insufficient resources is non-critical activity, the project cost will increase unnecessarily. Due to the fact that the non-critical activity is able to be delay within its total float, it does not affect the project finish time. Consequently, the project cost is not affected automatically.

In the Fig. 2, it demonstrates the simple examples. In this regard, the activities B, C and D are proceeded parallelly. This results in the exceed of resource $\mathrm{R} 1$ on the fourth and fifth day of work. The first solution to solve this problem is to use 4 units of R2 to replace 2 units of insufficient R1 and 2 units of R2 to replace one-unit of insufficient $\mathrm{R} 1$ on the fourth day and the fifth day of work respectively. The result of project finish time from the first solution in fact is not different from the second solution which is going to described below.

The second solution deals with the insufficient resources R1. This solution opts to have one-day delay of activity D which has lower priority than activity B and C.

Then one-unit insufficient R1 of activity D is replaced with 2 units of resources R2 on the fifth and sixth day of work. Since activity D is still considered as non-critical activity on the fourth day of work because one day of total float is left, the delay of activity D only one day does not have an effect on the project finish time.

Comparing between the first solution and the second solution, it is clearly shown that the result of project cost deriving from the second solution is cheaper than the first solution. This is due to the fact that the second solution tries to reduce the quantity and chances of using unnecessary resource replacement.

In brief, before deciding to replace insufficient resources with multi- skilled resources and/or external resources, it is important to consider whether the insufficient resource activity is the non - critical activity or not. The fact that the non - critical activity can be delayed within its total float, it is, therefore, does not affect the project finish time. To be precise, the delay of non-critical activity having insufficient resources within its total float is the better solution when compared with the resource replacement solution because of its ability to reduce the unnecessary cost.

\section{Project cost consideration}

Even if the existing multi-skilled resource-constrained project scheduling causes the fastest project finish time, it does not include the cheapest project cost. The use of the lower productivity resources employed by the multi- skilled resources to replace the insufficient resources is the crucial evidence 
proving that the multi-skilled resource- constrained project brings about the increase of resources cost which finally leads to the increase of the project cost.

In Fig. 2 the study shows the third solution. This solution attempts to solve the problem of insufficient resources R1 by two-day delaying activity $\mathrm{D}$ which has lower priority than activity B and C. Next, one-unit of insufficient resources R1 is replaced with 2 units of resources $\mathrm{R} 2$ on the sixth day. This solution, although, is slower than the second solution 1 day, the project finish time is still within the contract time. When consider about the project cost, it is found the project cost of the third of solution is cheaper than the second solution. The question is if the activity $\mathrm{D}$ is delayed one more day from the sixth day, what will happen. Will the project cost be reduced the same way as the third solution? The answer is not at all. On the contrary, the project cost increases. What is worse is that the project finish time delays from the contract time which means that the construction project are supposed to pay for penalty cost.

Therefore, in order to reach the goals of the construction project: the minimum project cost and the earliest project finish time, it is necessary to compare between the resource replacement cost and the one-day delaying activity cost. The result of the comparison will be used in the decision-making process to select the best solution for the problem.

\section{COST-RESOURCE REPLACEMENT TRADE-OFF ALGORITHM (CRT ALGORITHM)}

Cost-resource replacement trade-off algorithm (CRT algorithm) is the procedure which is developed to overcome the limitations of the existing heuristic approach as shown in Fig. 3. CRT algorithm begins with the critical path method calculation. Then the resource assignment step is conducted by allocating available resources to the eligible activities according to their priority order. During the resource assignment step if the available resources are found to be insufficient for the given requirement of an eligible activity, CRT algorithm will trade-off the result of the project finish time and the project cost between the two alternatives: the resource replacement and the one- day delaying activity. Tradeoff stage of CRT algorithm can be divided into 3 categories as follows.

\section{Total float of an eligible activity is greater than 0.}

In this category, if an eligible activity having insufficient resources has remaining total float, to delay this particular activity within its remaining total float is compulsory. The delay of a non-critical activity is allowed to do because it does not have any effect on the project finish time and the project cost as well.

\section{The total float of an eligible activity is equal to 0 , but the project float is greater than 0.}

In this category, the total float of an eligible activity having insufficient resources remains 0 . The delay of the Particular activity just only one-day results in not only the increase of the one-day project finish time but also the increase of the project cost. The increasing project cost comes from the increasing cost of indirect cost and opportunity cost. However, since the project float between the project finish time and the contract time is greater than 0 , the penalty cost is not applicable. Thus, before deciding to delay an eligible activity having insufficient resource, the trade-off procedure between the resource replacement cost and the total cost of the increasing indirect cost and opportunity cost derived from the one-day delaying of an eligible activity having insufficient resource is required. If the result of the resource replacement cost is more expensive than the one-day delaying activity cost, delaying that particular activity to the next decision point is regarded as the appropriate choice as the resource replacement in this situation leads to the increase of the project cost. In contrast to the mentioned situation, if the result of the resource replacement cost is cheaper than the one-day delaying activity cost, the resource replacement is considered the suitable alternative.

\section{The total float of an eligible activity and the project float equal to 0}

In this category, the one-day delay of an eligible activity having insufficient resource and 0 total float (critical activity) does not cause only one-day increase of the project finish time, it also brings about penalty cost in addition to indirect and opportunity cost. The penalty cost originates from the fact that the project float of the given situation is 0 . When the project float becomes 0 , the one-day delay of a critical activity results in the exceeding of the project finish time from the contract time. Drawing from the above reasons, it is important to note that before deciding to delay the particular critical activity, the remaining days of the project float needs to be taken into account. In the given situation that the remaining days of the project float does not exist any longer, it is necessary to tradeoff the resource replacement cost and the one-day delaying activity cost coming from indirect cost, opportunity cost and penalty cost. The result of trade-off determines the directions of decision making process. If the resource replacement cost is more expensive than the one-day delaying activity cost, the critical activity can be delayed to the next decision point. But if the result of the resource replacement cost is cheaper than the one-day delaying activity cost, the resource replacement is regarded as the proper choice.

When the available resources are allocated for the eligible activities at the current decision point by CRT algorithm, the critical path method (CPM) will be recalculated to update the information of the activities before stepping into the next decision point. According to procedure showed in Fig. 3, the next decision point can be calculated from the 1,2 and 3 equations. However, the different situations employ different equations. In the first situation which the total float of the delayed activities is greater than 0 , the next decision point will be calculated from the earliest time between the times which the total float of the delayed activities is changed to 0 and the finish times of the activities being able to start from the last decision point. The second situation which the total float of the 
delayed activities is equal to zero and the project float of the last decision point is greater than zero, the next decision point will be calculated from the earliest time between the time which the project float of the last decision point is changed to 0 and the finish times of the activities being able to start from the last decision point. In the third situation which both the total float of the delayed activities and the project float of the last decision point are equal to zero, the next decision point will be calculated from the earliest finish times among the activities being able to start from the last decision point. After finding out the next decision point, then the resources which once were assigned for the completed activities at the last decision point will be returned to the resource pool. Later, the next eligible activities will be selected for the new resource assignment step following their priority order. Meanwhile, if it is found that the resources are not enough for an eligible activity, the trade-off process will be introduced again. Finally, when the allocation of resources for all activities with CRT algorithm is completed, the start and finish time of activities, the daily resources utilization, the project finish time and the project cost are the final result.

\section{PROJECT CASE STUDY}

The information of the case study includes daily resource requirement of the activities, daily available resources, daily resource cost, daily indirect cost, daily penalty cost, the contract time and the multi-skilled resource replacement rules as shown in Table 1. It also assumes that the external resource cost is doubled price when compared with the internal resource cost. However, the opportunity cost arising from the delay of the project finish time is not taken into consideration so that it would simplify the calculation.

The case study begins with the initial CPM calculation, which does not consider the limitation of available resources. The result of the initial project finish time from initial CPM calculation is forty-nine days. Thus, when comparison is made between the initial project finish time and the contract time (fifty days), the initial project float has one-day left.

\section{CRT algorithm with multi-skilled resource replacement (CRT-MRR)}

This CRT algorithm is in fact based its calculation on the idea that the external resource replacement is not allowed. During the resource assignment step, if it is found that the insufficient resources problem needs the resource replacement, only the remaining multi-skilled resources will be considered. Meanwhile, if the quantities or the total cost of the remaining multi-skilled resources cannot fulfill the insufficient resources in an activity, this activity has to be delayed to the next decision point. The simplified table demonstrated RTS with multiskilled resource replacement (RTS-MRR) applied the heuristic priority rule of the earliest finish time is shown in Table 2.

From the Table 7, when each decision point of column 1 is considered, the eligible activities of column 2 will be selected on ground of precedence relationship. In column 3, the priority value of each eligible activity is calculated from the earliest finish time of itself. According to the earliest finish time rule, the lower priority value the eligible activity holds, the higher priority order it has. The eligible activities at each decision point are arranged on the rows according to their priority order. The number of the daily available resources R1, R2, R3, R4 and R5 are shown on the top of columns 4567 and 8 respectively. The numbers shown in column 4-8 indicate the number of the resources assigned for the eligible activities. The minus numbers in the parentheses are the number of insufficient resources. The total float of the eligible activities in column 9, the project float in column 10, the additional indirect cost in column 11 , the additional penalty cost in column 12 , the multiskilled resource replacement cost in column 13, and the external resource replacement cost in column 14 are used to trade off before to decide whether to replace the insufficient resources or to delay the activity. The results of the decision making is shown in column 16 . If any activity can be started on the current decision point, its finish time in column 17 is calculated from the sum of the current decision point in column 1 and its duration in column 15.

On the first day of the project, there are the eligible activities $\mathrm{C}, \mathrm{B}$ and A arranged by their priority order. When the resource assignment step is proceeded following the priority order, activity $\mathrm{C}$ and $\mathrm{B}$ can be started because the available resources are sufficient. Consequently, the remaining resources are not enough for the requirement of activity A. Due to the remaining total float of activity A, it can be delayed within its total float, and hence it does not affect the project finish time. Then, the next decision point is identified by the earliest time between the time which the total float of an activity $\mathrm{A}$ is changed to 0 (on the third day) and the finish time of activity $\mathrm{C}$ (the fifth day) and $\mathrm{B}$ (the seventh day). Therefore, the next decision point is on the third day. Before continuing the resource assignment on the third day, CPM is recalculated. The result of CPM recalculation brings out the fact that the project finish time still remains forty-nine days and the project float is one day. Nevertheless, the total float of an activity $\mathrm{A}$ is 0 . Owing to the fact that on the third day, the eligible activities are the activities $\mathrm{C}, \mathrm{B}$ and $\mathrm{A}$ arranged by their priority order, the activities $\mathrm{C}$ and $\mathrm{B}$ can be continued with available resources from the first day. This leads to insufficient resources R2 for activity A. As an activity A has 0 total float, it is imperative that other resources have to be found in order to replace two units of insufficient resource $\mathrm{R} 2$. The fact that resource $\mathrm{R} 3$ and $\mathrm{R} 4$ can be replace insufficient resource R2 but their quantity is not enough and the other external resources R2 are not allowed to replace insufficient resource R2. As a result, an activity A has to be delayed to the next decision point. Then the next decision point becomes the fourth day which the project float is changed to 0 . Before continuing the resource assignment on the fourth day, CPM is recalculated. The result of CPM recalculation brings out the fact that the project finish time is delayed to fifty days and the project float is changed to 0 . On the fourth day, the quantity of the remaining resource R3 and R4 is still not enough for replacing two units of insufficient resource R2 for activity A. Based on this result, an activity A has to be delayed to the next decision point on the fifth day. On the fifth day, because the remaining resources $\mathrm{R} 4$ are enough for replacing one-unit insufficient resource $\mathrm{R} 2$ of activity A, the trading off between the one-day delaying activity A cost and two units of resource 
$\mathrm{R} 4$ cost is conducted. The trade-off process reveals that the oneday delaying activity A cost is more expensive than the cost of two units of resource R4. Following this result, two units of resource $\mathrm{R} 4$ are used for replacing of two units of insufficient resource R2 in activity A. Automatically, activity A can be started from the seventh day and finish on the fourteenth day. The process is repeatedly operated through all of the cycles until all activities are scheduled. Finally, this results in sixtyone days of project finish time, and five hundred eighty-nine thousand and six hundred baht of project cost.

\section{CRT with multi-skilled resource and external resource replacement (CRT-MRR/ERR)}

The simplified table demonstrated RTS with multi-skilled resource and external resource replacement (RTS-MRR/ERR) applied the heuristic priority rule of the earliest finish time is shown in Table 3. During the CRT algorithm, if it is found that the insufficient resources problem needs the resource replacement, both of the multi-skilled resources and the external resource will be considered.

On the first day of the project, there are the eligible activities $\mathrm{C}, \mathrm{B}$ and A arranged by their priority order. When the resource assignment step is proceeded following the priority order, activity $\mathrm{C}$ and $\mathrm{B}$ can be started because the available resources are sufficient. Consequently, the remaining resources are not enough for the requirement of activity A. Due to the remaining total float of activity A, it can be delayed within its total float, and hence it does not affect the project finish time. Then, the next decision point is identified by the earliest time between the time which the total float of an activity $\mathrm{A}$ is changed to 0 (on the third day) and the finish time of activity $\mathrm{C}$ (the fifth day) and $\mathrm{B}$ (the seventh day). Therefore, the next decision point is on the third day. Before continuing the resource assignment on the third day, CPM is recalculated. The result of CPM recalculation brings out the fact that the project finish time still remains forty-nine days and the project float is one day. Nevertheless, the total float of an activity A is 0 . Owing to the fact that on the third day, the eligible activities still involve in the activities $\mathrm{C}, \mathrm{B}$ and $\mathrm{A}$ arranged by their priority order, the activities $\mathrm{C}$ and $\mathrm{B}$ can be continued with available resources. This leads to insufficient resources R2 for activity A. As an activity $\mathrm{A}$ has 0 total float, it is imperative that other resources have to be found in order to replace two units of insufficient resources $\mathrm{R} 2$. The fact that resource $\mathrm{R} 3$ and $\mathrm{R} 4$ can be replace insufficient resource R2 but their quantity is not enough, the external resources R2 are considered as another option. However, before going through the process of using R2, tradeoff between the external resource R2 cost with the one-day delaying activity A cost needs to be pursued. The one-day delaying activity A cost includes only the additional indirect cost because the project float is greater than 0 . It is found that the 2 units of external resource R 2 cost is more expensive than the one-day delaying activity A cost. As a result, an activity A has to be delayed to the next decision point. Then the next decision point becomes the fourth day which the project float is changed to 0 . Before continuing the resource assignment on the fourth day, CPM is recalculated. The result of CPM recalculation brings out the fact that the project finish time is delayed to fifty days and the project float is changed to 0 . On the fourth day when the project float is 0 , the one-day delaying activity A does not only cause the additional indirect cost but brings about the additional penalty cost as well. With this reason, the one-day delaying activity A cost on the fourth day is more expensive than the cost of using two units of external resource R2 for replacing two units of insufficient resource R2. The replacement of two units of insufficient resource R2 with two units of external resource R2 makes an activity A being able to start on the fourth day. Subsequently, the next decision point is identified on the fifth day, the finish time of activity $C$. Before continuing the resource assignment on the fifth day, CPM is recalculated.

The result of CPM recalculation brings out the fact that the project finish time still remains fifty days and the project float is 0 . On the fifth day, because the remaining resources $\mathrm{R} 4$ are enough for replacing one-unit insufficient resource $\mathrm{R} 2$ of activity A, the trading off between the one-day delaying activity A cost and two units of resource R4 cost is conducted. The trade-off process reveals that the one-day delaying activity A cost is more expensive than the cost of two units of resource R4. Following this result, two units of resource R4 are used for replacing of two units of insufficient resource R2 in activity A. Automatically, activity A can be continued from the fourth to the seventh day. The seventh day, then becomes the next decision point which is the finish time of activity B. Before continuing the resource assignment on the seventh day, CPM is recalculated. The result of CPM recalculation brings out the fact that the project finish time still remains fifty days and the project float is 0 . Nevertheless, the total float of an activity A is 0 . On this particular day, there are additional eligible activities $\mathrm{E}, \mathrm{G}$ and $\mathrm{F}$ arranged by their priority order. The eligible activities $\mathrm{A}$ and $\mathrm{E}$ can be started with the available resources but the remaining resources are not enough for activities $G$ and $F$. Since the activities $G$ and $F$ still have remaining its total float, it is possible for the activities to be delayed until the next decision point on the eighth day when the total float of activity $\mathrm{F}$ is changed to 0 . Before continuing the resource assignment on the eighth day, CPM is recalculated. The result of CPM recalculation brings out the fact that the project finish time still remains fifty days and the project float is 0 . Due to the fact that on the eighth day, the eligible activities still involve in the activities A, E, G and F arranged by their priority order, the activities $\mathrm{A}$ and $\mathrm{E}$ can be continued with available resources and hence they can be finished on the thirteenth and seventeenth day, respectively. This leads to insufficient resources R2 for activities F and G. Owing to the remaining total float of activity $\mathrm{G}$, it can be delayed within its total float without effecting the project finish time. On the contrary, an activity $\mathrm{F}$ has 0 total float, it is imperative that other resources have to be found in order to replace the two units of insufficient resources $\mathrm{R} 2$. The fact that resource R3 and $\mathrm{R} 4$ can be replace insufficient resources $\mathrm{R} 2$ and their remaining quantity is still enough, the trading off between the one-day delaying activity $\mathrm{F}$ cost and the total cost of two units of resource R3 and two units of resource R4 is conducted. The trade-off process provides the evidence that the one-day delaying activity $\mathrm{F}$ cost is more expensive than the total cost of two units of resource R3 and two units of resource R4. Based on this result, two units of resource R3 and two units of 
resource R4 are used to replace the two units of insufficient resource R2 in activity F. Unavoidably, activity F can be started on the eighth day and finished on the twenty-second day. The process is repeatedly operated through all of the cycles until all activities are scheduled. Finally, this results in fifty days of project finish time, and five hundred seventy-one thousand and six hundred baht of project cost.

\section{Case Study Analysis}

CRT algorithm is experimented with nineteen heuristic priority rules as previously shown in Table 4 . The results of project finish time and project cost from two categories of CRT algorithm are compared with the existing heuristic approaches and commercial scheduling software, MS project, as shown in Table 5.

As a result of project finish time demonstrated in Table 5, the existing multi-skilled resource scheduling provides faster project finish time than MS project and the existing singleskilled resource scheduling. The cause of faster project finish time relies on the fact that the existing multi-skilled resource scheduling tries to avoid delaying the critical activity having insufficient resources by searching for the remaining qualified multi-skilled resources to replace the insufficient resources. Nevertheless, if the quantities of remaining qualified multiskilled resources are not enough, the existing multi-skilled resource scheduling will immediately delay this critical activity and hence the project finish time will be delayed. In the same situation, before deciding to delay the critical activity having insufficient resources, RTS-MRR/ERR will try to find out qualified external resources to replace insufficient resources. For example, it is noticeable in Table 3 that on the fourth day, a critical activity A has the two units of insufficient resource $\mathrm{R} 2$ and also the quantities of the qualified resources R3 and R4 are not enough to solve the problem. Unlike multi-skill resource scheduling, RTS-MRR/ERR is able to solve the insufficient resources with two units of external resource R2. Its result can save the project finish time by avoiding unnecessary delay the critical activity. It is worth mentioning that, although, RTS-MRR provides the result of faster project finish time when compared with MS project and the existing single-skilled resource scheduling, its result may not be faster than the existing multi-skilled resource scheduling. The reason is in any decision point, RTS-MRR can delay the critical activity having insufficient resources if the resource replacement cost is more expensive than the one-day delaying activity cost.

As a result of project cost demonstrated in Table 5, the existing multi-skilled resource scheduling provides more expensive project cost than MS project and the existing single-skilled resource scheduling. The reason supporting the result is the existing multi-skilled resource scheduling bases its decision on the use of the remaining of multi-skilled resources to replace the insufficient resources immediately. If the activity having insufficient resources is non-critical activity, it can be delayed within its total float. Therefore, it can be concluded that, the use of the lower productivity resources for the replacement of insufficient resources for non-critical activity may bring about the unnecessarily increasing project cost. In contrast to the existing multi-skilled resource scheduling, CRT algorithm considers whether that the activity having insufficient resources is non-critical activity or not by examining its remaining total float. If it is non-critical activity, CRT algorithm can delay it within its total float without affecting the project finish time. Consequently, the project cost naturally is not affected. To summarize, RST procedure provides cheaper project cost than what existing multi-skilled resource scheduling can do. For example, the fact in Table 3 insists that on the seventh day, the remaining resource $\mathrm{R} 2$ are not enough for activity $G$. Being different from multi-skill resource scheduling, CRT algorithm decides to delay non-critical $\mathrm{G}$ for three days but not beyond its total float. Accordingly, the project finish time still remains fifty days but it can save 600 baht of two units of resource R4 cost to replace one unit of insufficient resource R2. Furthermore, CRT algorithm has the trade-off process for considering the worthiness between delaying the activity having insufficient resources and replacing insufficient resources alternative. This all processes make CRT algorithm to provide more advantages of the faster project finish time and cheaper project cost when compared with the existing heuristic approach as it has the better ability in decision making of the resource scheduling.

\section{CONCLUSION AND RECOMMENDATION}

CRT algorithm is a heuristic approach for resource scheduling consisting of the rigorous sequence of resource assignment and the solutions of insufficient resources where the resulting time and the cost are taken into consideration. It also focuses on the concept of checking the critical or non-critical activity and the trading-off the worthiness between the alternatives of solving insufficient resource. In addition to the multi-skilled resource replacement, CRT algorithm simultaneously offers external resource replacement in order to increase the starting opportunity for the critical activity. The results on various heuristic priorities rules demonstrate that CRT algorithm can significantly reduce the project finish time and the project cost while comparing with existing heuristic approach. Moreover, it offers manifold benefits including better job stability for workers and higher flexibility for work assignment.

In spite of this, when it comes to the practical aspect, the success CRT algorithm greatly relies on the ability of the project managers to properly utilize multi-skilled and external workers to fit certain activities. The managers do not only need to put the right man on the right job, but also should contemplate on the continuity of each individual worker on the activity he/she performs. Apart from what has been mentioned, in order to ensure that workers are really multi-skilled, trainings and tests should be provided by an enterprise on a regular basis.

Like other processes, CRT algorithm is still under certain limitations. It overlooks the overtime work and omits the change of construction methods in solving insufficient resources. What is more, it is currently validated only to the finish-to-start relationship. Those interested in the further study are able to implement CRT algorithm on other types of relationship with additional lag and lead times. 


\section{REFERENCES}

[1] Alvarez-Valdes, R. and J.M. Tamarit, Heuristic Algorithms for Resource-Constrained Project Scheduling: A Review and an Empirical Analysis. In: Slowinski, R. and J. Weglarz (Eds.): Advances in Project Scheduling. Elsevier, Amsterdam (1989) 113134.

[2] Bedworth, D.O., Industrial Systems: Planning, Analysis, Control. Ronald Press, New York (1973).

[3] Boctor F. F., An adaptation of the simulated annealing algorithm for solving resource-constrained project scheduling problems, International Journal of Production Research 34 (1996) 2335-2351.

[4] Boctor, F.F., Some Efficient Multi-Heuristic Procedures for Resource-Constrained Project Scheduling. European Journal of Operational Research 49 (1990) 3-13.

[5] Bouleimen K., and Lecocq H., A new efficient simulated annealing algorithm for the resourceconstrained project scheduling problem and its multiple mode version, European Journal of Operational Research 149 (2003) 268-281.

[6] Brand, J.D.; W.L. Meyer, and L.R. Shaffer, The Resource Scheduling Method for Construction. Civil Engineering Studies Report No.5, University ofIllinois (1964).

[7] Brucker P., Drexl A., Mohring R., Neumann K., and Pesch E., Resource-constrained project scheduling: Notation, classification, models, and methods, European Journal of Operational Research 112 (1) (1999) 3-41.

[8] Cho J. H. and Kim Y. D., A simulated annealing algorithm for resource-constrained project scheduling problems, Journal of the Operational Research Society 48 (1997) 736-744.

[9] Davis, E.W. and J.H. Patterson, A Comparison of Heuristic and Optimum Solutions in ResourceConstrained Project Scheduling. Management Science 21(1975) 944-955.

[10] Elmaghraby, S., Resource allocation via dynamic programming in activity networks, European Journal of Operational Research 64 (2) (1993) 199-215.

[11] Elsayed, E.A. and N.Z. Nasr, Heuristics for ResourceConstrained Project Scheduling. International Journal of Production Research 24 (1986) 299-310.

[12] Hartmann S. and Kolisch R., "Experimental evaluation of state-of-the-art heuristics for the resourceconstrained project scheduling problem", European Journal of Operational Research, 127 (2000) 394-407.

[13] Hartmann S., A competitive genetic algorithm for the resource-constrained project scheduling, Naval Research Logistics 456 (1998) 733-750.

[14] Hartmann S., A self-adapting genetic algorithm for project scheduling under resource constraints, Naval Research Logistics 49 (2002) 433-448.
[15] Hegazy, T., Optimization of resource allocation and leveling using genetic algorithms, Journal of Construction Engineering and Management, 125 (3) (1999) 167-175.

[16] Hegazy T.,Shabeeb A., El-beltagi E., Cheema T., Algorithm for scheduling with multi-skilled construction resources, Journal of Construction Engineering and Management 126 (6) (2000) 125-133.

[17] Herroelen W., Demeulemeester E., and De Reyck B., Resource- constrained project scheduling: A survey of recent developments, Computers \& Operations Research 25 (4) (1998) 279-302.

[18] Hindi K. S., Yang H., and Fleszar K., An evolutionary algorithm for resource-constrained project scheduling, IEEE Transactions on Evolutionary Computation 6 (2002) 512-518.

[19] Icmeli, O.; S. Selcuk Erenguc, and Ch.1. Zappe, Project Scheduling Problems: A Survey. International Journal of Operations \& Production Management 13(1993) 8091.

[20] Jiang, G., and Shi, J., Exact algorithm for solving project scheduling problems under multiple resource constraints, Journal of Construction Engineering and Management, 131(9) (2005) 986-992.

[21] Klein, R., Bidirectional Planning: Improving Priority Rule-Based Heuristics for Scheduling ResourceConstrained Projects, European Journal of Operational Research 127 (2000) 619-638.

[22] Klein, R., Scheduling of Resource-Constrained Projects, Operations Research/Conputer Science Interfaces Series 10 (2000) 181-187.

[23] Kolisch R. and Hartmann S., Experimental investigation of heuristics for resource-constrained project scheduling: An update, European Journal of Operational Research, (2005), forthcoming.

[24] Kolisch R., and Padman R., An integrated survey of deterministic project scheduling. OMEGA 29 (2001) 249-272.

[25] Kolisch, R., Efficient Priority Rules for the ResourceConstrained Project Scheduling Problem. Journal of Operations Management 14 (1996) 179-192.

[26] Kolisch, R., Project Scheduling under Resource Constraints - Efficient Heuristics for Several Problem Classes. Physica, Heidelberg (1995)

[27] Lee J.-K. and Kim Y.-D., Search heuristics for resourceconstrained project scheduling, Journal of the Operational Research Society 47 (1996) 678-689.

[28] Liu, Y., S. Zhao, X. Du and S. Li., Optimization of Resource Allocation in Construction Using Genetic Algorithms, Machine Learning and Cybernetics 6 (2005) 3428-3432.

[29] Merkle D., Middendorf M., and Schmeck H.. Ant colony optimization for resource-constrained project 
scheduling, IEEE Transactions on Evolutionary Computation 6 (2002) 333-346.

[30] Patterson J.H., and Huber W.D., A horizon-varying, zero-one approach to project scheduling, Management Science 20 (1974) 990-998.

[31] Patterson J.H., and Roth G.W., Scheduling a project under multiple resource constraints: a zero-one programming approach." AIIE Transactions 8 (1976) 449-55.

[32] Pinson E., Prins C., and Rullier F., Using tabu search for solving the resource-constrained project scheduling problem, in: Proceedings of the 4th International Workshop on Project Management and Scheduling, Leuven, Belgium (1994) 102-106.

[33] Pritsker A.A.B., Watters L.J., and Wolfe P.M., Multiproject scheduling with limited resources: a zeroone programming approach, Management Science 16 (1969) 93-107.

[34] Son, J., and Mattila, K., Binary resource leveling model: Activity splitting allowed, Journal of Construction Engineering and Management, 130 (6) (2004) 887-894.

[35] Son, J., and Skibniewski, M., Multiheuristic approach for resource leveling problem in construction engineering: Hybrid approach, Journal of Construction Engineering and Management 125 (1) (1999) 23-31.

[36] Thomas P. R. and Salhi S., A tabu search approach for the resource constrained project scheduling problem, Journal of Heuristics 4 (1998) 123-139.

[37] Thomas, P.R. and S. Salhi, An Investigation into the Relationship of Heuristic Performance with NetworkResource Characteristics. Journal of the Operational Research Society 48 (1997) 34-43.

[38] Toklu Y. C., Application of genetic algorithms to construction scheduling with or without resource constraints, Canadian Journal of Civil Engineering 29 (2002) 421-429.

[39] Ulusoy, G. and L.Ozdamar, Heuristic Performance and Network/Resource Characteristics in ResourceConstrained Project Scheduling. Journal of the Operational Research Society 40 (1989) 1145-1152.

[40] Wongwai, N. and S. Malaikrisanachalee, Augmented Heuristic Algorithm for Multi-skilled Resource Scheduling, Automation in Construction 20(4) (2011) 429-445.

Table 1. Case study data

\begin{tabular}{llllllll}
\hline Activity & Duration & Predecessor & \multicolumn{5}{c}{ Daily Resource Requirement } \\
\cline { 5 - 8 } & (days) & & R1 & R2 & R3 & R4 & R5 \\
\hline $\mathrm{A}$ & 9 & - & 2 & 2 & 4 & 1 & 2 \\
$\mathrm{~B}$ & 7 & - & 2 & 3 & 5 & 2 & 1 \\
$\mathrm{C}$ & 5 & - & 1 & 1 & 2 & 1 & 1 \\
$\mathrm{D}$ & 11 & $\mathrm{~A}, \mathrm{~B}$ & 1 & 2 & 4 & 0 & 1 \\
$\mathrm{E}$ & 10 & $\mathrm{~B}$ & 1 & 2 & 3 & 2 & 1 \\
$\mathrm{~F}$ & 14 & $\mathrm{~B}$ & 0 & 2 & 3 & 2 & 1 \\
$\mathrm{G}$ & 12 & $\mathrm{~B}, \mathrm{C}$ & 2 & 1 & 2 & 1 & 0 \\
$\mathrm{H}$ & 12 & $\mathrm{D}, \mathrm{E}$ & 1 & 0 & 1 & 1 & 1 \\
$\mathrm{I}$ & 10 & $\mathrm{D}, \mathrm{F}$ & 2 & 2 & 3 & 0 & 1 \\
$\mathrm{~J}$ & 11 & $\mathrm{E}, \mathrm{G}$ & 3 & 1 & 0 & 2 & 2 \\
$\mathrm{~K}$ & 13 & $\mathrm{~F}, \mathrm{G}$ & 1 & 3 & 7 & 1 & 1 \\
$\mathrm{~L}$ & 15 & $\mathrm{~J}, \mathrm{~K}$ & 3 & 3 & 4 & 2 & 3 \\
M & $\mathrm{H}, \mathrm{I}$ & 4 & 2 & 5 & 1 & 2 \\
\hline Daily resource available (units/day) & 10 & 4 & 12 & 7 & 10 \\
\multicolumn{2}{l}{ Daily resource cost (/day) } & & 300 & 400 & 400 & 300 & 300 \\
\multicolumn{2}{l}{ Daily indirect cost (/day) } & & 1,000 & & & & \\
\multicolumn{2}{l}{ Daily penalty cost (/day) } & & 2,500 & & & & \\
Contract duration (days) & & 50 & & & & \\
\hline
\end{tabular}

Substitution rules: 2R3=1R2, 2R4=1R2, 2R5=1R4 
Table 2. Simplified table of CRT-MRR using earliest finish time priority rule

\begin{tabular}{|c|c|c|c|c|c|c|c|c|c|c|c|c|c|c|c|c|c|}
\hline & & & & & esources & & & & & & & & & & & & \\
\hline $\mathbf{T}^{\mathrm{a}}$ & & $\mathbf{P}^{\mathbf{c}}$ & & & & & & $\mathbf{T F}^{\mathrm{d}}$ & $\mathbf{P F}^{\mathrm{e}}$ & $\mathbf{C}_{i}^{\mathbf{f}}$ & $\mathbf{C}_{p^{g}}$ & $\mathbf{C}_{\mathbf{m}} \mathbf{h}$ & $\mathrm{Ce}^{\mathrm{i}}$ & $D^{j}$ & Decision & $F^{k}$ & Replacement \\
\hline & & & $\mathbf{R} 1=10$ & $R 2=4$ & $\mathrm{R3}=12$ & $\mathrm{R} 4=7$ & $R 5=10$ & & & & & & & & & & \\
\hline (1) & (2) & (3) & (4) & (5) & (6) & (7) & (8) & (9) & (10) & (11) & (12) & (13) & (14) & (15) & (16) & (17) & (18) \\
\hline 0 & $\mathrm{C}$ & 5 & 1 & 1 & 2 & 1 & 1 & 4 & 1 & & & & & 5 & Start & & \\
\hline & B & 7 & 2 & 3 & 5 & 2 & 1 & 0 & & & & & & 7 & Start & & \\
\hline & A & 9 & 2 & $2(-2)$ & 4 & 1 & 2 & 3 & & & & & & 9 & Delay & & \\
\hline 3 & $\mathrm{C}$ & & 1 & 1 & 2 & 1 & 1 & 4 & 1 & & & & & 5 & Continue & & \\
\hline & B & & 2 & 3 & 5 & 2 & 1 & 0 & & & & & & 7 & Continue & & \\
\hline & A & 9 & 2 & $2(-2)$ & 4 & 1 & 2 & 0 & & & & & & 9 & Delay & & \\
\hline 4 & $\mathrm{C}$ & & 1 & 1 & 2 & 1 & 1 & 5 & 0 & & & & & 5 & Continue & 5 & \\
\hline & B & & 2 & 3 & 5 & 2 & 1 & 1 & & & & & & 7 & Continue & & \\
\hline & A & 9 & 2 & $2(-2)$ & 4 & 1 & 2 & 0 & & & & & & 9 & Delay & & \\
\hline 5 & B & & 2 & 3 & 5 & 2 & 1 & 2 & 0 & & & & & 7 & Continue & 7 & \\
\hline & A & 9 & 2 & $2(-1)+1$ & 4 & $1+2$ & 2 & 0 & & 1,000 & 2,500 & 600 & & 9 & Start & & $2 \mathrm{R} 4=1 \mathrm{R} 2$ \\
\hline 7 & A & & 2 & 2 & 4 & 1 & 2 & 0 & 0 & & & & & 9 & Continue & & \\
\hline & $\mathrm{E}$ & 17 & 1 & 2 & 3 & 2 & 1 & 8 & & & & & & 10 & Start & & \\
\hline & G & 19 & 2 & $1(-1)$ & 2 & 1 & 0 & 4 & & & & & & 12 & Delay & & \\
\hline & $\mathrm{F}$ & 21 & 0 & $2(-2)$ & 3 & 2 & 1 & 2 & & & & & & 14 & Delay & & \\
\hline 9 & A & & 2 & 2 & 4 & 1 & 2 & 0 & 0 & & & & & 9 & Continue & & \\
\hline & $\mathrm{E}$ & 17 & 1 & 2 & 3 & 2 & 1 & 8 & & & & & & 10 & Start & & \\
\hline & G & 19 & 2 & $1(-1)$ & $2(-2)$ & $1(-1)$ & 0 & 2 & & & & & & 12 & Delay & & \\
\hline & $\mathrm{F}$ & 21 & 0 & $2(-2)+2$ & $3+2$ & $2+2$ & 1 & 0 & & 1,000 & 2,500 & 1,400 & & 14 & Start & & $2 \mathrm{R} 3=1 \mathrm{R} 2,2 \mathrm{R} 4=1 \mathrm{R} 2$ \\
\hline 11 & $\mathrm{~A}$ & & 2 & 2 & 4 & 1 & 2 & 0 & 0 & & & & & 9 & Continue & 14 & \\
\hline & $\mathrm{E}$ & & 1 & 2 & 3 & 2 & 1 & 8 & & & & & & 10 & Continue & & \\
\hline & $\mathrm{F}$ & & 0 & $2(-2)+2$ & $3+2$ & $2+2$ & 1 & 0 & & 1,000 & 2,500 & 1,400 & & 14 & Continue & & $2 \mathrm{R} 3=1 \mathrm{R} 2,2 \mathrm{R} 4=1 \mathrm{R} 2$ \\
\hline & G & 19 & 2 & $1(-1)$ & $2(-2)$ & $1(-1)$ & 0 & 0 & & & & & & 12 & Delay & & \\
\hline 14 & $\mathrm{E}$ & & 1 & 2 & 3 & 2 & 1 & 11 & 0 & & & & & 10 & Continue & 17 & \\
\hline & $\mathrm{F}$ & & 0 & 2 & 3 & 2 & 1 & 3 & & & & & & 14 & Continue & & \\
\hline & G & 19 & 2 & $1(-1)+1$ & 2 & $1+2$ & 0 & 0 & & 1,000 & 2,500 & 600 & & 12 & Start & & $2 \mathrm{R} 4=1 \mathrm{R} 2$ \\
\hline & $\mathrm{D}$ & 20 & 1 & $2(-2)$ & 4 & 0 & 1 & 3 & & & & & & 11 & Delay & & \\
\hline
\end{tabular}




\begin{tabular}{|c|c|c|c|c|c|c|c|c|c|c|c|c|c|c|c|c|c|}
\hline & & & & & esource & & & & & & & & & & & & \\
\hline $\mathbf{T}^{\mathbf{a}}$ & $\mathbf{A}^{\mathbf{b}}$ & $\mathbf{P}^{\mathbf{c}}$ & & & & & & $-\mathbf{T F}^{\mathbf{d}}$ & $\mathbf{P F}^{\mathrm{e}}$ & $\mathbf{C}_{\mathbf{i}}^{\mathbf{f}}$ & $\mathbf{C}_{p^{g}}$ & $\mathbf{C}_{\mathbf{m}}{ }^{\mathrm{h}}$ & $\mathrm{C}_{\mathrm{e}}^{\mathrm{i}}$ & $D^{j}$ & Decision & $\mathbf{F}^{\mathbf{k}}$ & Replacement \\
\hline & & & $\mathbf{R} 1=10$ & $R 2=4$ & $R 3=12$ & $\mathrm{R} 4=7$ & R5=10 & & & & & & & & & & \\
\hline (1) ( & (2) & (3) & (4) & (5) & (6) & (7) & (8) & (9) & (10) & (11) & (12) & (13) & (14) & (15) & (16) & (17) & (18) \\
\hline 17 & $\mathrm{~F}$ & & 0 & 2 & 3 & 2 & 1 & 3 & 0 & & & & & 14 & Continue & 23 & \\
\hline & G & & 2 & 1 & 2 & 1 & 0 & 0 & & & & & & 12 & Continue & & \\
\hline & $\mathrm{D}$ & 20 & 1 & $2(-1)+1$ & 4 & $0+2$ & 1 & 0 & & 1,000 & 2,500 & 600 & & 11 & Start & & $2 \mathrm{R} 4=1 \mathrm{R} 2$ \\
\hline 23 & G & & 2 & 1 & 2 & 1 & 0 & 0 & & & & & & 12 & Continue & 26 & \\
\hline & $\mathrm{D}$ & & 1 & 2 & 4 & 0 & 1 & 0 & & & & & & 11 & Continue & & \\
\hline 26 & $\mathrm{D}$ & & 1 & 2 & 4 & 0 & 1 & 0 & & & & & & 11 & Continue & 28 & \\
\hline & $\mathrm{J}$ & 30 & 3 & 1 & 0 & 2 & 2 & 2 & & & & & & 11 & Start & & \\
\hline & K & 34 & 1 & $3(-2)+2$ & 7 & $1+4$ & 1 & 0 & & 1,000 & 2,500 & 1,200 & & 13 & Start & & $4 \mathrm{R} 4=2 \mathrm{R} 2$ \\
\hline 28 & $\mathrm{~J}$ & & 3 & 1 & 0 & 2 & 2 & 2 & & & & & & 11 & Continue & & \\
\hline & $\mathrm{K}$ & & 1 & 3 & 7 & 1 & 1 & 0 & & & & & & 13 & Continue & & \\
\hline & I & 31 & 2 & $2(-2)$ & 3 & 0 & 1 & 2 & & & & & & 10 & Delay & & \\
\hline & $\mathrm{H}$ & 32 & 1 & 0 & 1 & 1 & 1 & 0 & & & & & & 12 & Start & & \\
\hline 30 & $\mathrm{~J}$ & & 3 & 1 & 0 & 2 & 2 & 2 & & & & & & 11 & Continue & 37 & \\
\hline & $\mathrm{K}$ & & 1 & 3 & 7 & 1 & 1 & 0 & & & & & & 13 & Continue & & \\
\hline & $\mathrm{H}$ & & 1 & 0 & 1 & 1 & 1 & 0 & & & & & & 12 & Continue & & \\
\hline & I & 31 & 2 & $2(-2)$ & 3 & 0 & 1 & 0 & & & & & & 10 & Delay & & \\
\hline 37 & $\mathrm{~K}$ & & 1 & 3 & 7 & 1 & 1 & 7 & & & & & & 13 & Continue & 39 & \\
\hline & $\mathrm{H}$ & & 1 & 0 & 1 & 1 & 1 & 7 & & & & & & 12 & Continue & & \\
\hline & I & 31 & 2 & $2(-1)+1$ & 3 & $0+2$ & 1 & 0 & & 1,000 & 2,500 & 600 & & 10 & Start & & $2 \mathrm{R} 4=1 \mathrm{R} 2$ \\
\hline 39 & $\mathrm{H}$ & & 1 & 0 & 1 & 1 & 1 & 7 & & & & & & 12 & Continue & 40 & \\
\hline & I & & 2 & 2 & 3 & 0 & 1 & 0 & & & & & & 10 & Continue & & \\
\hline & $\mathrm{L}$ & 49 & 3 & $3(-1)$ & 4 & 2 & 3 & 7 & & & & & & 15 & Delay & & \\
\hline 40 & I & & 2 & 2 & 3 & 0 & 1 & 0 & & & & & & 10 & Continue & & \\
\hline & $\mathrm{L}$ & 49 & 3 & $3(-1)$ & 4 & 2 & 3 & 6 & & & & & & 15 & Delay & & \\
\hline 46 & I & & 2 & 2 & 3 & 0 & 1 & 0 & & & & & & 10 & Continue & 47 & \\
\hline & $\mathrm{L}$ & 49 & 3 & $3(-1)+1$ & 4 & $2+2$ & 3 & 0 & & 1,000 & 2,500 & 600 & & 15 & Start & & $2 \mathrm{R} 4=1 \mathrm{R} 2$ \\
\hline 47 & $\mathrm{~L}$ & & 3 & 3 & 4 & 2 & 3 & 0 & & & & & & 15 & Continue & 61 & \\
\hline & M & 46 & 4 & $2(-1)+1$ & 5 & $1+2$ & 2 & 0 & & 1,000 & 2,500 & 600 & & 14 & Start & 61 & $2 \mathrm{R} 4=1 \mathrm{R} 2$ \\
\hline
\end{tabular}


${ }^{\mathrm{a}}$ Time, ${ }^{\mathrm{b}}$ Eligible activity, ${ }^{\mathrm{c}}$ Priority Value, ${ }^{\mathrm{d}}$ Total float, ${ }^{\mathrm{e}}$ Project float, ${ }^{\mathrm{f}}$ Additional indirect cost, ${ }^{\mathrm{g}}$ Additional penalty cost, ${ }^{\mathrm{h}} \mathrm{Multi}-$ skilled resource replacement cost, ${ }^{\mathrm{i} E x t e r n a l}$ resource replacement cost, ${ }^{\mathrm{j} A c t i v i t y ~ d u r a t i o n, ~}{ }^{\mathrm{k}}$ Finish time

Project cost $(589,600)=$ Resource cost $(474,900)+$ Multi-skilled resource replacement cost $(26,200)+$ External resource replacement cost $(0)+$ Indirect cost $(61,000)+$ Penalty cost $(27,500)$

Table 3. Simplified table of RTS-MRR/ERR using earliest finish time priority rule

\begin{tabular}{|c|c|c|c|c|c|c|c|c|c|c|c|c|c|c|c|c|c|}
\hline \multirow{3}{*}{\multicolumn{2}{|c|}{$\begin{array}{l}T^{a} A^{b} \\
\text { (1) (2) }\end{array}$}} & \multirow{3}{*}{$\begin{array}{l}\mathbf{P}^{\mathbf{c}} \\
\text { (3) }\end{array}$} & \multicolumn{5}{|c|}{ Resources } & \multirow{3}{*}{$\begin{array}{l}\mathbf{T F}^{\mathrm{d}} \\
\text { (9) }\end{array}$} & \multirow{3}{*}{$\begin{array}{l}\mathbf{P F}^{\mathrm{e}} \\
(10)\end{array}$} & \multirow{3}{*}{$\begin{array}{c}\mathrm{C}_{\mathbf{i}}^{\mathbf{f}} \\
(11)\end{array}$} & \multirow{3}{*}{$\begin{array}{l}\mathbf{C}_{p^{g}} \\
\text { (12) }\end{array}$} & \multirow{3}{*}{$\begin{array}{l}\mathrm{C}_{\mathrm{m}}^{\mathrm{h}} \\
\text { (13) }\end{array}$} & \multirow{3}{*}{$\begin{array}{l}\mathrm{Ce}^{\mathrm{i}} \\
\text { (14) }\end{array}$} & \multirow{3}{*}{$\begin{array}{c}D^{j} \\
(15)\end{array}$} & \multirow{3}{*}{$\begin{array}{l}\text { Decision } \\
\text { (16) }\end{array}$} & \multirow{3}{*}{$\begin{array}{l}\mathbf{F}^{\mathbf{k}} \\
(17)\end{array}$} & \multirow[t]{3}{*}{ Replacement } \\
\hline & & & $\mathbf{R} 1=\mathbf{1 0}$ & $R 2=4$ & $\mathrm{R} 3=12$ & R4=7 & $R 5=10$ & & & & & & & & & & \\
\hline & & & (4) & (5) & (6) & (7) & (8) & & & & & & & & & & \\
\hline \multirow[t]{3}{*}{0} & $\mathrm{C}$ & 5 & 1 & 1 & 2 & 1 & 1 & 4 & 1 & & & & & 5 & Start & 5 & \\
\hline & B & 7 & 2 & 3 & 5 & 2 & 1 & 0 & & & & & & 7 & Start & 7 & \\
\hline & A & 9 & 2 & $2(-2)$ & 4 & 1 & 2 & 3 & & & & & & 9 & Delay & & \\
\hline \multirow[t]{3}{*}{3} & $\mathrm{C}$ & & 1 & 1 & 2 & 1 & 1 & 4 & 1 & & & & & 5 & Continue & 5 & \\
\hline & B & & 2 & 3 & 5 & 2 & 1 & 0 & & & & & & 7 & Continue & 7 & \\
\hline & A & 12 & 2 & $2(-2)$ & 4 & 1 & 2 & 0 & & 1,000 & & & 1,600 & 9 & Delay & & \\
\hline \multirow[t]{3}{*}{4} & $\mathrm{C}$ & & 1 & 1 & 2 & 1 & 1 & 5 & 0 & & & & & 5 & Continue & 5 & \\
\hline & B & & 2 & 3 & 5 & 2 & 1 & 1 & & & & & & 7 & Continue & 7 & \\
\hline & A & 13 & 2 & $2(-2)+2$ & 4 & 1 & 2 & 0 & & 1,000 & 2,500 & & 1,600 & 9 & Start & 13 & Ext.2R2 \\
\hline \multirow[t]{2}{*}{5} & B & & 2 & 3 & 5 & 2 & 1 & 1 & 0 & & & & & 7 & Continue & 7 & \\
\hline & A & & 2 & $2(-1)+1$ & 4 & $1+2$ & 2 & 0 & & 1,000 & 2,500 & 600 & & 9 & Continue & 13 & $2 \mathrm{R} 4=1 \mathrm{R} 2$ \\
\hline \multirow[t]{4}{*}{7} & A & & 2 & 2 & 4 & 1 & 2 & 0 & 0 & & & & & 9 & Continue & 13 & \\
\hline & $\mathrm{E}$ & 17 & 1 & 2 & 3 & 2 & 1 & 7 & & & & & & 10 & Start & 17 & \\
\hline & G & 19 & 2 & $1(-1)$ & 2 & 1 & 0 & 3 & & & & & & 12 & Delay & & \\
\hline & $\mathrm{F}$ & 21 & 0 & $2(-2)$ & 3 & 2 & 1 & 1 & & & & & & 14 & Delay & & \\
\hline \multirow[t]{4}{*}{8} & A & & 2 & 2 & 4 & 1 & 2 & 0 & 0 & & & & & 9 & Continue & 13 & \\
\hline & $\mathrm{E}$ & & 1 & 2 & 3 & 2 & 1 & 7 & & & & & & 10 & Continue & 17 & \\
\hline & G & 19 & 2 & $1(-1)$ & $2(-2)$ & $1(-1)$ & 0 & 2 & & & & & & 12 & Delay & & \\
\hline & $\mathrm{F}$ & 21 & 0 & $2(-2)+2$ & $3+2$ & $2+2$ & 1 & 0 & & 1,000 & 2,500 & 1,400 & & 14 & Start & 22 & $2 \mathrm{R} 3=1 \mathrm{R} 2,2 \mathrm{R} 4=1 \mathrm{R} 2$ \\
\hline \multirow[t]{4}{*}{10} & A & & 2 & 2 & 4 & 1 & 2 & 0 & 0 & & & & & 9 & Continue & 13 & \\
\hline & $\mathrm{E}$ & & 1 & 2 & 3 & 2 & 1 & 7 & & & & & & 10 & Continue & 17 & \\
\hline & $\mathrm{F}$ & & 0 & $2(-2)+2$ & $3+2$ & $2+2$ & 1 & 0 & & 1,000 & 2,500 & 1,400 & & 14 & Continue & 22 & $2 \mathrm{R} 3=1 \mathrm{R} 2,2 \mathrm{R} 4=1 \mathrm{R} 2$ \\
\hline & G & 19 & 2 & $1(-1)+1$ & $2(-2)+2$ & $1(-1)+1$ & 0 & 0 & & 1,000 & 2,500 & & 3,000 & 12 & Start & 22 & Ext1R2,Ext2R3,Ext1R4 \\
\hline \multirow[t]{4}{*}{13} & $\mathrm{E}$ & & 1 & 2 & 3 & 2 & 1 & 7 & 0 & & & & & 10 & Continue & 17 & \\
\hline & $\mathrm{F}$ & & 0 & 2 & 3 & 2 & 1 & 0 & & & & & & 14 & Continue & 22 & \\
\hline & G & & 2 & $1(-1)+1$ & 2 & $1+2$ & 0 & 0 & & 1,000 & 2,500 & 600 & & 12 & Continue & 22 & $2 \mathrm{R} 4=1 \mathrm{R} 2$ \\
\hline & D & 20 & 1 & $2(-2)+2$ & 4 & 0 & 1 & 0 & & 1,000 & 2,500 & & 1,600 & 11 & Start & 24 & Ext.2R2 \\
\hline
\end{tabular}




\begin{tabular}{|c|c|c|c|c|c|c|c|c|c|c|c|c|c|c|c|c|c|}
\hline \multirow{3}{*}{\multicolumn{2}{|c|}{$\begin{array}{l}T^{a} A^{1} \\
\text { (1) }(2\end{array}$}} & \multirow{3}{*}{$\begin{array}{l}\mathbf{P}^{\mathbf{c}} \\
\text { (3) }\end{array}$} & \multicolumn{5}{|c|}{ Resources } & \multirow{3}{*}{$\begin{array}{l}\mathbf{T F}^{\mathrm{d}} \\
-\quad(9)\end{array}$} & \multirow{3}{*}{$\begin{array}{l}\mathbf{P F}^{\mathrm{e}} \\
\text { (10) }\end{array}$} & \multirow{3}{*}{$\begin{array}{l}\mathbf{C}_{\mathbf{i}}^{\mathbf{f}} \\
\text { (11) }\end{array}$} & \multirow{3}{*}{$\begin{array}{l}\mathbf{C}_{\mathbf{p}^{\mathrm{g}}} \\
\text { (12) }\end{array}$} & \multirow{3}{*}{$\begin{array}{l}\mathrm{Cm}^{\mathrm{h}} \\
\text { (13) }\end{array}$} & \multirow{3}{*}{$\begin{array}{l}\mathrm{C}_{\mathrm{e}}^{\mathrm{i}} \\
(14)\end{array}$} & \multirow{3}{*}{$\begin{array}{c}D^{\mathbf{j}} \\
\text { (15) }\end{array}$} & \multirow{3}{*}{$\begin{array}{l}\text { Decision } \\
\text { (16) }\end{array}$} & \multirow{3}{*}{$\begin{array}{l}\mathbf{F}^{\mathrm{k}} \\
\text { (17) }\end{array}$} & \multirow{3}{*}{$\begin{array}{c}\text { Replacement } \\
\text { (18) }\end{array}$} \\
\hline & & & $R 1=10$ & $R 2=4$ & $R 3=12$ & R4=7 & $R 5=10$ & & & & & & & & & & \\
\hline & & & (4) & (5) & (6) & (7) & (8) & & & & & & & & & & \\
\hline \multirow[t]{3}{*}{17} & $\mathrm{~F}$ & & 0 & 2 & 3 & 2 & 1 & 0 & 0 & & & & & 14 & Continue & 22 & \\
\hline & G & & 2 & 1 & 2 & 1 & 0 & 0 & & & & & & 12 & Continue & 22 & \\
\hline & D & 20 & 1 & $2(-1)+1$ & 4 & $0+2$ & 1 & 0 & & 1,000 & 2,500 & 600 & & 11 & Continue & 24 & $2 \mathrm{R} 4=1 \mathrm{R} 2$ \\
\hline \multirow[t]{3}{*}{22} & $\mathrm{D}$ & & 1 & 2 & 4 & 0 & 1 & 0 & 0 & & & & & 11 & Continue & 24 & \\
\hline & $\mathrm{J}$ & 30 & 3 & 1 & 0 & 2 & 2 & 2 & & & & & & 11 & Start & 33 & \\
\hline & $\mathrm{K}$ & 34 & 1 & $3(-2)+2$ & 7 & $1+4$ & 1 & 0 & & 1,000 & 2,500 & 1,200 & & 13 & Start & 35 & $4 \mathrm{R} 4=2 \mathrm{R} 2$ \\
\hline \multirow[t]{4}{*}{24} & $\mathrm{~J}$ & & 3 & 1 & 0 & 2 & 2 & 2 & 0 & & & & & 11 & Continue & 33 & \\
\hline & $\mathrm{K}$ & & 1 & 3 & 7 & 1 & 1 & 0 & & & & & & 13 & Continue & 35 & \\
\hline & I & 31 & 2 & $2(-2)$ & 3 & 0 & 1 & 2 & & & & & & 10 & Delay & & \\
\hline & $\mathrm{H}$ & 32 & 1 & 0 & 1 & 1 & 1 & 0 & & & & & & 12 & Start & 35 & \\
\hline \multirow[t]{4}{*}{26} & $\mathrm{~J}$ & & 3 & 1 & 0 & 2 & 2 & 2 & 0 & & & & & 11 & Continue & 33 & \\
\hline & $\mathrm{K}$ & & 1 & 3 & 7 & 1 & 1 & 0 & & & & & & 13 & Continue & 35 & \\
\hline & $\mathrm{H}$ & & 1 & 0 & 1 & 1 & 1 & 0 & & & & & & 12 & Continue & 36 & \\
\hline & I & 31 & 2 & $2(-2)+2$ & 3 & 0 & 1 & 0 & & 1,000 & 2,500 & & 1,600 & 10 & Start & 36 & Ext.2R2 \\
\hline \multirow[t]{3}{*}{33} & K & & 1 & 3 & 7 & 1 & 1 & 0 & 0 & & & & & 13 & Continue & 35 & \\
\hline & $\mathrm{H}$ & & 1 & 0 & 1 & 1 & 1 & 0 & & & & & & 12 & Continue & 35 & \\
\hline & I & & 2 & $2(-1)+1$ & 3 & $0+2$ & 1 & 0 & & 1,000 & 2,500 & 600 & & 10 & Continue & 36 & $2 \mathrm{R} 4=1 \mathrm{R} 2$ \\
\hline \multirow[t]{2}{*}{35} & I & & 2 & 2 & 3 & 0 & 1 & 0 & 0 & & & & & 10 & Continue & 36 & \\
\hline & $\mathrm{L}$ & 49 & 3 & $3(-1)+1$ & 4 & $2+2$ & 3 & 0 & & 1,000 & 2,500 & 600 & & 15 & Start & 50 & $2 \mathrm{R} 4=1 \mathrm{R} 2$ \\
\hline \multirow[t]{2}{*}{36} & $\mathrm{~L}$ & & 3 & 3 & 4 & 2 & 3 & 0 & 0 & & & & & 15 & Continue & 50 & \\
\hline & M & 46 & 4 & $2(-1)+1$ & 5 & $1+2$ & 2 & 0 & & 1,000 & 2,500 & 600 & & 14 & Start & 50 & $2 \mathrm{R} 4=1 \mathrm{R} 2$ \\
\hline
\end{tabular}

aime, ${ }^{b}$ Eligible activity, ${ }^{\mathrm{c} P r i o r i t y}$ Value, ${ }^{\mathrm{d}}$ Total float, ${ }^{\mathrm{e}}$ Project float, ${ }^{\mathrm{f}}$ Additional indirect cost, ${ }^{\mathrm{g}}$ Additional penalty cost, ${ }^{\mathrm{h}}$ Multiskilled resource replacement cost, ${ }^{i}$ External resource replacement cost, ${ }^{\mathrm{j}}$ Activity duration, ${ }^{\mathrm{k}}$ Finish time

Project cost $(571,600)=$ Resource cost $(467,200)+$ Multi-skilled resource replacement cost $(26,200)+$ External resource replacement cost $(28,200)+$ Indirect cost $(50,000)+$ Penalty cost $(0)$ 
Table 4. Heuristic rules

\section{Heuristic Rules}

\section{Network-Based Rules}

Shortage Processing Time (SPT)

Most Immediate Successors (MIS)

Most Total Successors (MTS)

Greatest Rank Positional Weight (GRPW)

Greatest Rank Positional Weight all (GRPW*)

\section{Critical Path-Based Rules}

Early Start Time (EST)

Early Finish Time (EFT)

Early Start Time (Dynamically) (ESTD)

Early Finish Time (Dynamically) (EFTD)

Late Start Time (LST)

Late Finish Time (LFT)

Minimum Slack Time (MSL)

Minimum Slack Time (Dynamically) (MSLD)

\section{Resource-Based Rules}

Greatest Resource Demand (GRD)

Weighted Resource Utilization and Precedence (WRUP)

\section{Composite Rules}

ACROS

ACTRES

TIMROS

TIMRES

\section{Regret-Based Rules}

Improved Resource Scheduling Method (IRSM)

Worst Case Slack Time Rule (WCS)

Average Case Slack Time Rule (ACS)

Worst Case Latest Starting Time (WCLS) $\min \mathrm{ESj}$

\section{Priority}

$\min d_{j}$

$\max \left|F_{j}\right|$

$\max \left|F_{j}^{*}\right|$

$\max d_{j}+\sum_{i \in F_{j}} d_{i}$

$\max d_{j}+\sum_{i \in F_{j}^{*}} d_{i}$

$\min \mathrm{EFj}$

$\min \mathrm{ESj}(\mathrm{PS})$

$\min \mathrm{EF}_{\mathrm{j}}(\mathrm{PS})$

$\min \mathrm{LSj}$

$\min \mathrm{LFj}$

$\min \mathrm{TFj}$

$\min \mathrm{TFj}(\mathrm{PS})$

$\max \mathrm{d}_{\mathrm{j}} \cdot \sum_{\mathrm{r}=1}^{\mathrm{m}} \mathrm{u}_{\mathrm{jr}}$

$\max \omega .\left|F_{j}\right|+(1-\omega) \cdot \sum_{r=1}^{m} u_{j r} / a_{r}$ $\max \left\{\sum_{\mathrm{i} \square \Pi_{\mathrm{jh}}} \sum_{\mathrm{r}=1}^{\mathrm{m}} \mathrm{u}_{\mathrm{ir}} / \mathrm{a}_{\mathrm{r}}\right\}=\mathrm{acr}_{\mathrm{j}}$

$\max \left\{\sum_{\mathrm{i} \square \Pi_{\mathrm{jh}}} \sum_{\mathrm{r}=1}^{\mathrm{m}} \mathrm{u}_{\mathrm{ir}} \cdot \mathrm{d}_{\mathrm{i}} / \mathrm{a}_{\mathrm{r}}\right\}=\mathrm{act}_{\mathrm{j}}$

$\max \omega \cdot \frac{\mathrm{LS}_{\mathrm{n}}-\mathrm{LS}_{\mathrm{j}}}{\mathrm{LS}_{\mathrm{n}}-\mathrm{LS}_{1}}+(1-\omega) \cdot \frac{\mathrm{acr}_{\mathrm{j}}}{\mathrm{acr}_{1}}$

$\max \omega \cdot \frac{\mathrm{LS}_{\mathrm{n}}-\mathrm{LS} \mathrm{S}_{\mathrm{j}}}{\mathrm{LS}_{\mathrm{n}}-\mathrm{LS} S_{1}}+(1-\omega) \cdot \frac{\mathrm{act}_{\mathrm{j}}}{\text { act }_{1}}$ 
Table 5. Results comparison

\begin{tabular}{|c|c|c|c|c|c|c|c|c|}
\hline \multirow[t]{2}{*}{ Priority Rules } & \multicolumn{4}{|c|}{ Time (days) } & \multicolumn{4}{|c|}{ Cost (Million) } \\
\hline & $\overline{\mathrm{SRS}^{\mathrm{a}}}$ & $\mathrm{MRS}^{\mathrm{b}}$ & $\mathrm{RTS}_{1}^{\mathrm{c}}$ & $\mathrm{RTS}_{2}{ }^{\mathrm{d}}$ & $\mathrm{SRS}^{\mathrm{a}}$ & $\mathrm{MRS}^{\mathrm{b}}$ & $\mathrm{RTS}_{1}^{\mathrm{c}}$ & $\mathrm{RTS}_{2}{ }^{\mathrm{d}}$ \\
\hline 1.SPT & 93 & 59 & 50 & 61 & 0.692 & 0.700 & 0.572 & 0.590 \\
\hline 2.MIS & 93 & 73 & 51 & 61 & 0.692 & 0.700 & 0.569 & 0.590 \\
\hline 3.MTS & 82 & 61 & 51 & 61 & 0.654 & 0.662 & 0.569 & 0.590 \\
\hline 4.GRPW & 93 & 72 & 51 & 62 & 0.692 & 0.700 & 0.575 & 0.591 \\
\hline 5.GRPW* & 89 & 61 & 51 & 62 & 0.678 & 0.686 & 0.567 & 0.591 \\
\hline 6.EST & 93 & 59 & 50 & 59 & 0.692 & 0.700 & 0.561 & 0.584 \\
\hline 7.EFT & 94 & 59 & 50 & 61 & 0.696 & 0.704 & 0.571 & 0.590 \\
\hline 8.ESTD & 92 & 60 & 50 & 59 & 0.689 & 0.697 & 0.562 & 0.582 \\
\hline 9.EFTD & 93 & 59 & 50 & 61 & 0.692 & 0.700 & 0.571 & 0.590 \\
\hline 10.LST & 84 & 58 & 52 & 59 & 0.661 & 0.669 & 0.567 & 0.579 \\
\hline 11.LFT & 84 & 62 & 52 & 59 & 0.661 & 0.669 & 0.567 & 0.579 \\
\hline 12.MSL & 91 & 58 & 52 & 59 & 0.685 & 0.693 & 0.567 & 0.579 \\
\hline 13.MSLD & 84 & 58 & 52 & 59 & 0.661 & 0.669 & 0.567 & 0.579 \\
\hline 14.GRD & 89 & 72 & 50 & 59 & 0.678 & 0.686 & 0.561 & 0.582 \\
\hline 15.WRUP & 93 & 72 & 51 & 59 & 0.692 & 0.700 & 0.559 & 0.582 \\
\hline 16.ACROS & 91 & 56 & 52 & 59 & 0.685 & 0.693 & 0.567 & 0.579 \\
\hline 17.ACTRES & 91 & 56 & 52 & 59 & 0.685 & 0.693 & 0.567 & 0.579 \\
\hline 18.TIMROS & 93 & 56 & 52 & 62 & 0.692 & 0.700 & 0.566 & 0.588 \\
\hline 19.TIMRES & 93 & 56 & 52 & 62 & 0.692 & 0.700 & 0.566 & 0.588 \\
\hline 20.MS Project & 92 & - & & & 0.689 & - & - & \\
\hline
\end{tabular}

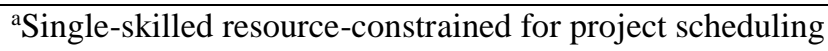

${ }^{b}$ Multi-skilled resource-constrained for project scheduling

${ }^{\mathrm{c}}$ Resource replacement trade-off for project scheduling with multi-skilled resource replacement

${ }^{\mathrm{d}}$ Resource replacement trade-off for project scheduling with multi-skilled resource and external resource replacement
} 
Cost

: R1 ( $\left.\boldsymbol{W}_{1}\right)$ cost $300, \mathrm{R} 2\left(\dot{\mathrm{W}}_{2}\right)$ cost 300 ,

Indirect cost 700/day,

Penalty cost $1,000 /$ day

Replacement : 2R2 $=1 \mathrm{R} 1$

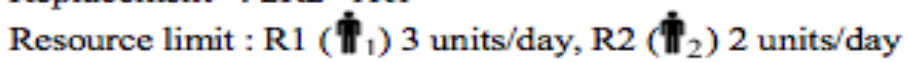

\begin{tabular}{|c|c|c|c|c|c|c|c|c|c|}
\hline \multirow{2}{*}{ Activity } & \multirow{2}{*}{$\begin{array}{c}\text { Priority } \\
\text { value }\end{array}$} & \multicolumn{8}{|c|}{ Unlimited resource scheduling } \\
\hline & & 1 & 2 & 3 & 4 & 5 & 6 & 7 & 8 \\
\hline A & 4 & $\phi_{1} \phi_{1}$ & $\phi_{1} \boldsymbol{\phi}_{1}$ & & & & & & \\
\hline B & 3 & & & $t_{1}$ & $t_{1} \mathbf{t}_{1}$ & & & & \\
\hline C & 2 & & & $\mathbf{t}_{1}$ & $t_{1} \boldsymbol{1}_{1}$ & $\mathbf{t}_{1}$ & & & \\
\hline D & 1 & & & & & & $\$_{1}$ & & \\
\hline $\mathrm{R}$ & & 2 & 2 & 4 & 4 & 2 & 2 & & \\
\hline
\end{tabular}

R1 limit of 3 units/day exceeded on day 3 and 4 .

Total cost $=16 \times 300(\mathrm{R} 1$ cost $)+6 \times 700$ (indirect cost $)=9,000$

\begin{tabular}{|c|c|c|c|c|c|c|c|c|c|}
\hline \multirow{2}{*}{ Activity } & \multirow{2}{*}{$\begin{array}{c}\text { Priority } \\
\text { values }\end{array}$} & \multicolumn{8}{|c|}{ First solution } \\
\hline & & 1 & 2 & 3 & 4 & 5 & 6 & 7 & 8 \\
\hline A & 4 & $\phi_{1} \mathbf{1}_{1}$ & $\boldsymbol{\phi}_{1} \boldsymbol{\phi}_{1}$ & & & & & & \\
\hline B & 3 & & & $\boldsymbol{\phi}_{1}$ & $\phi_{1}$ & & & & \\
\hline C & 2 & & & & & $t_{1}$ & $\phi_{1}$ & $\$$ & \\
\hline $\mathrm{D}$ & 1 & & & & & & & & $\uparrow_{1}$ \\
\hline \multicolumn{2}{|c|}{ R1(3) } & 2 & 2 & 2 & 2 & 2 & 2 & 2 & 2 \\
\hline
\end{tabular}

Contract duration ( 7 days) is exceeded.

Total cost $=16 \times 300$ ( R1 cost) $+8 \times 700$ (indirect cost) $+1 \times 1,000$ (penalty cost) $=11,400$

\begin{tabular}{|c|c|c|c|c|c|c|c|c|c|}
\hline \multirow{2}{*}{ Activity } & \multirow{2}{*}{$\begin{array}{l}\text { Priority } \\
\text { values }\end{array}$} & \multicolumn{8}{|c|}{ Second solution } \\
\hline & & 1 & 2 & 3 & 4 & 5 & 6 & 7 & 8 \\
\hline A & 4 & $\phi_{1}$ & $\boldsymbol{\phi}_{1}$ & & & & & & \\
\hline B & 3 & & & 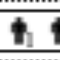 & 1 & & & & \\
\hline $\mathrm{C}$ & 2 & & & \#t & 1 & h & & & \\
\hline D & 1 & & & & & & $\mathbf{1}_{1}$ & & \\
\hline \multicolumn{2}{|c|}{ R1(3) } & 2 & 2 & 3 & 3 & 2 & 2 & & \\
\hline \multicolumn{2}{|c|}{$\mathrm{R} 2(2)$} & & & 2 & 2 & & & & \\
\hline
\end{tabular}

Contract duration ( 7 days) is met.

Total cost $=14 \times 300(\mathrm{R} 1$ cost $)+4 \times 400(\mathrm{R} 2$ cost $)+6 \times 700$ (indirect cost $)=$ 10,000

Figure 1. Limitation of critical activity consideration 


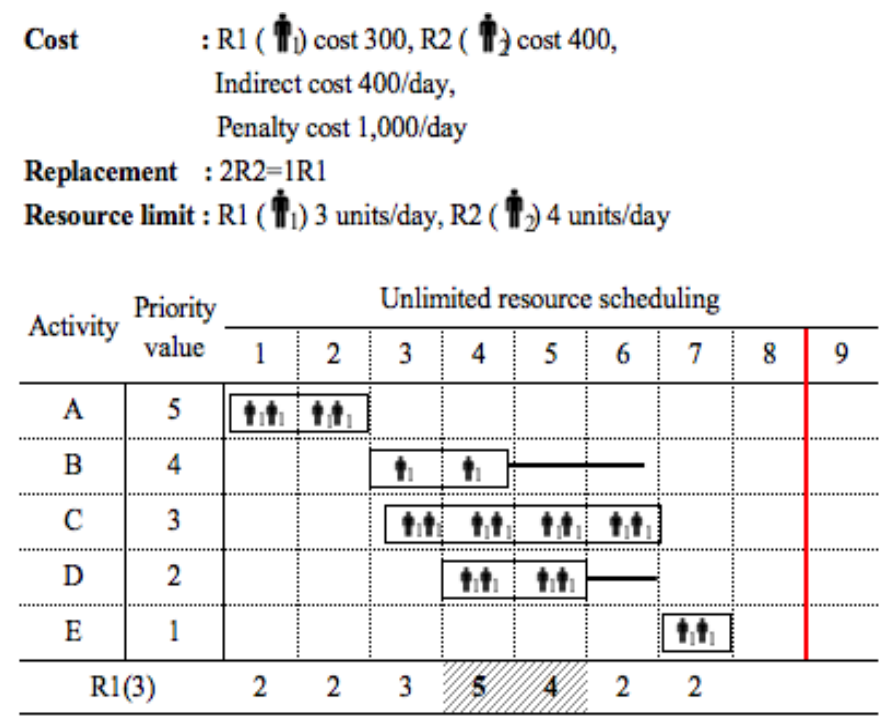

R1 limit of 3 units/day exceeded on day 4 and 5.

Total cost $=20 \times 300(\mathrm{R} 1$ cost $)+7 \times 700$ (indirect cost $)=10,900$

\begin{tabular}{|c|c|c|c|c|c|c|c|c|c|c|}
\hline \multirow{2}{*}{ Activity } & \multirow{2}{*}{$\begin{array}{c}\text { Priority } \\
\text { value }\end{array}$} & \multicolumn{9}{|c|}{$1^{\text {st }}$ solution } \\
\hline & & 1 & 2 & 3 & 4 & 5 & 6 & 7 & 8 & 9 \\
\hline A & 5 & $\phi_{1} \phi_{1}$ & $\phi_{1}$ & & & & & & & \\
\hline B & 4 & & & $\phi_{1}$ & $\phi_{1}$ & & & & & \\
\hline $\mathrm{C}$ & 3 & & & $\$$ & $\phi$ & $\phi_{1}$ & $\phi_{1}$ & & & \\
\hline D & 2 & & & & enth & tht & & & & \\
\hline $\mathrm{E}$ & 1 & & & & & & & $\phi_{1}$ & & \\
\hline \multicolumn{2}{|c|}{$\mathrm{Rl}(3)$} & 2 & 2 & 3 & 3 & 3 & 2 & 2 & & \\
\hline \multicolumn{2}{|c|}{$\mathrm{R} 2(4)$} & & & & 4 & 2 & & & & \\
\hline
\end{tabular}

Contract duration ( 8 days) is met,

Total cost $=17 \times 300(\mathrm{R} 1$ cost $)+6 \times 400(\mathrm{R} 2$ cost $)+7 \times 400$ (indirect cost) $=$ 10,300

\begin{tabular}{|c|c|c|c|c|c|c|c|c|c|c|}
\hline \multirow{2}{*}{ Activity } & \multirow{2}{*}{$\begin{array}{c}\text { Priority } \\
\text { value }\end{array}$} & \multicolumn{9}{|c|}{$2^{\text {nd }}$ solution } \\
\hline & & 1 & 2 & 3 & 4 & 5 & 6 & 7 & 8 & 9 \\
\hline $\mathrm{A}$ & 5 & $\phi_{1}$ & $\phi_{1}$ & & & & & & & \\
\hline B & 4 & & & $\phi$ & $\$$ & & & & & \\
\hline C & 3 & & & $\phi_{1}$ & $\phi$ & $\phi$ & 1 & & & \\
\hline D & 2 & & & & $\square$ & 中th & $\boldsymbol{\phi}_{\mathbf{1}} \mathbf{p}_{2}$ & & & \\
\hline $\mathrm{E}$ & 1 & & & & & & & $\phi_{1} \mathbf{\phi}_{1}$ & & \\
\hline \multicolumn{2}{|c|}{$\mathrm{R} 1(3)$} & 2 & 2 & 3 & 3 & 3 & 3 & 2 & & \\
\hline \multicolumn{2}{|c|}{$\mathrm{R} 2(4)$} & & & & & 2 & 2 & & & \\
\hline
\end{tabular}

Contract duration ( 8 days) is met,

\begin{tabular}{|c|c|c|c|c|c|c|c|c|c|c|}
\hline \multirow{2}{*}{ Activity } & \multirow{2}{*}{$\begin{array}{c}\text { Priority } \\
\text { value }\end{array}$} & \multicolumn{9}{|c|}{$3^{\text {rd }}$ solution } \\
\hline & & 1 & 2 & 3 & 4 & 5 & 6 & 7 & 8 & 9 \\
\hline A & 5 & $\boldsymbol{\phi}_{1} \mathbf{1}_{1}$ & $\phi_{1}$ & & & & & & & \\
\hline B & 4 & & & $\mathbf{\phi}_{1}$ & $\mathbf{P}_{1}$ & & & & & \\
\hline $\mathrm{C}$ & 3 & & & $\boldsymbol{1}_{1}$ & $\left.\right|_{1}$ & $\phi_{1}$ & $\phi_{1} \boldsymbol{H}_{1}$ & & & \\
\hline D & 2 & & & & & & 中+ & $\boldsymbol{\phi}_{1}$ & & \\
\hline $\mathrm{E}$ & 1 & & & & & & & & 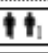 & \\
\hline \multicolumn{2}{|c|}{$\mathrm{R} 1(3)$} & 2 & 2 & 3 & 3 & 2 & 3 & 2 & 2 & \\
\hline \multicolumn{2}{|c|}{$\mathrm{R} 2(4)$} & & & & & & 2 & & & \\
\hline
\end{tabular}

Contract duration (8 days) is met,

Total cost $=19 \times 300(\mathrm{R} 1$ cost $)+2 \times 400(\mathrm{R} 2$ cost $)+8 \times 400$ (indirect cost) $=$ 9,700

Total cost $=18 \times 300(\mathrm{R} 1$ cost $)+4 \times 400(\mathrm{R} 2$ cost $)+7 \times 400$ (indirect cost) $=$

\begin{tabular}{|c|c|c|c|c|c|c|c|c|c|c|}
\hline \multirow{2}{*}{ Activity } & \multirow{2}{*}{$\begin{array}{c}\text { Priority } \\
\text { value }\end{array}$} & \multicolumn{9}{|c|}{$4^{\text {th }}$ solution } \\
\hline & & 1 & 2 & 3 & 4 & 5 & 6 & 7 & 8 & 9 \\
\hline A & 5 & $\phi_{1}$ & $\phi$ & & & & & & & \\
\hline B & 4 & & & $\boldsymbol{1}_{1}$ & $\mathbf{t}_{1}$ & & & & & \\
\hline $\mathrm{C}$ & 3 & & & 中l & 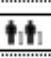 & $\phi_{1}$ & $\mathbf{1}_{1}$ & & & \\
\hline $\mathrm{D}$ & 2 & & & & & & & $\$$ & $\phi_{1} \boldsymbol{t}_{1}$ & \\
\hline E & 1 & & & & & & & & & 11 \\
\hline \multicolumn{2}{|c|}{ R1(3) } & 2 & 2 & 3 & 3 & 2 & 2 & 2 & 2 & 2 \\
\hline
\end{tabular}

Total cost $=20 \times 300(\mathrm{R} 1$ cost) $+9 \times 400$ (indirect cost) $+1 \times 1,000$ (penalty cost $)=10,600$

Figure 2. Limitation of non-critical activity and project cost consideration 


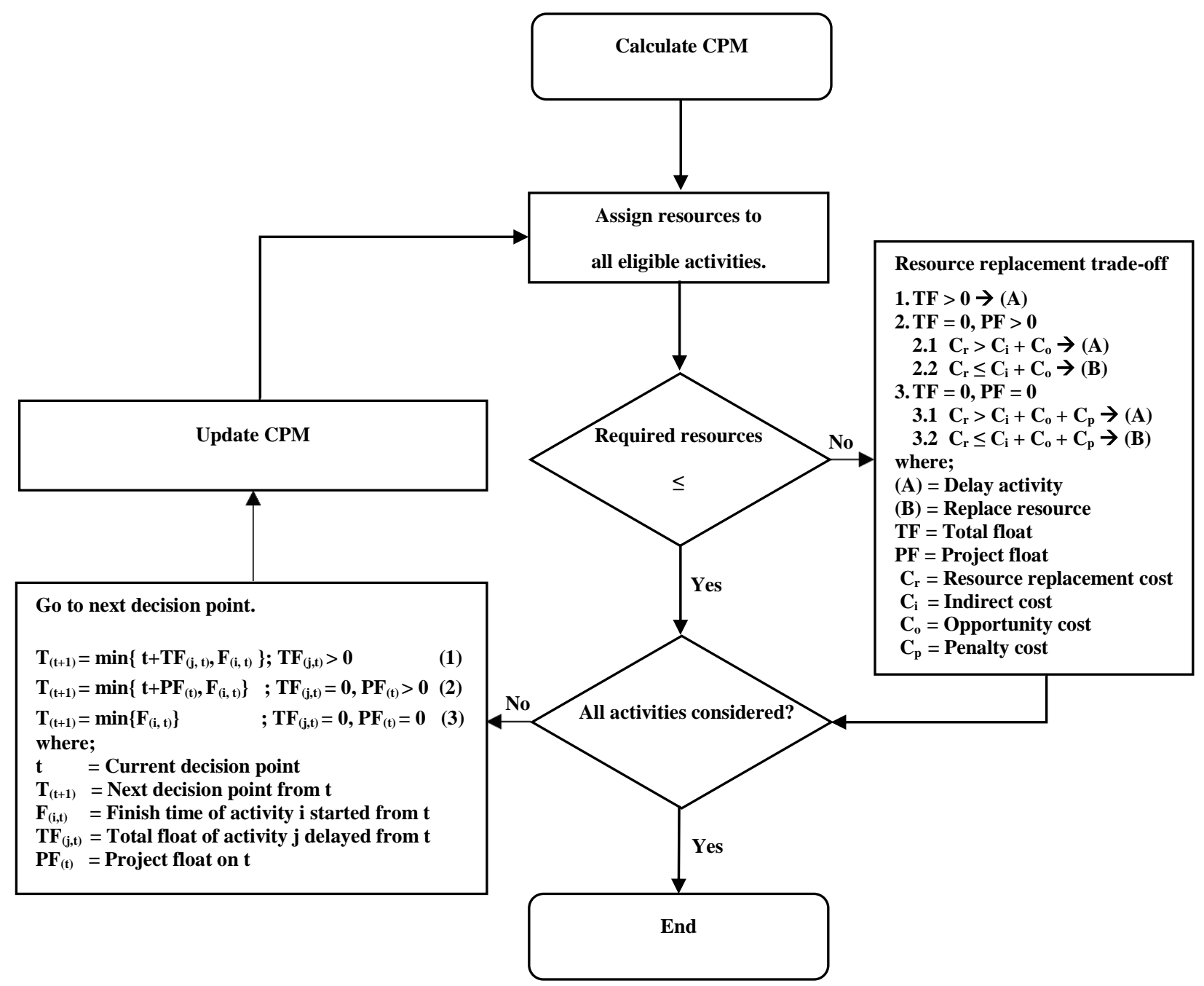

Figure 3. Cost-resource replacement trade-off algorithm 